\title{
Discovery, Biosynthesis and Heterologous Production of Loonamycin, a Potent Anticancer indolocarbazole alkaloid
}

Cheng Long Yang,,${ }^{\dagger}+$ Bo Zhang, ${ }^{\dagger},+$ Wen Wen Xue,${ }^{\dagger}$ Wu Li, ${ }^{\dagger}$ Zi Fei Xu, ${ }^{\dagger}$ Jing Shi, ${ }^{\dagger}$ Yan Shen, ${ }^{\dagger}$ Rui Hua Jiao, ${ }^{\dagger}$ Ren Xiang Tan,${ }^{\dagger}$ Hui Ming Ge* ${ }^{*}{ }^{\dagger}$

†State Key Laboratory of Pharmaceutical Biotechnology, Institute of Functional Biomolecules, Chemistry and Biomedicine Innovation Center (ChemBIC), School of Life Sciences, Nanjing University 210023, China

\section{Table of Contents}

Experimental Procedures

\author{
General \\ Strain isolation and identification \\ Bacterial strains, plasmids and culture conditions \\ Fermentation and extraction \\ Isolation of loonamycins \\ Construction of Cosmid library \\ Heterologous Expression and LC/MS detection \\ Cytotoxicity assay \\ Physical data for loonamycin (1-3)
}

Table S1. ${ }^{1} \mathrm{H}$ and ${ }^{13} \mathrm{C}$ NMR data for $\mathbf{1}$.

Table S2. ${ }^{1} \mathrm{H}$ and ${ }^{13} \mathrm{C}$ NMR data for 2.

Table S3. ${ }^{1} \mathrm{H}$ and ${ }^{13} \mathrm{C}$ NMR data for 3.

Table S4. Deduced functions of ORFs in the loo biosynthetic gene cluster.

Table S5. Primers used in this study.

Table S6. Cytotoxicity assay of $\mathbf{1}$.

Figure S1. HR-ESI-MS spectrum of $\mathbf{1}$.

Figure S2. ${ }^{1} \mathrm{H}$ NMR spectrum $(600 \mathrm{MHz})$ of 1 in DMSO- $d_{6}$.

Figure S3. ${ }^{13} \mathrm{C}$ NMR spectrum $(150 \mathrm{MHz})$ of 1 in DMSO- $d_{6}$.

Figure S4. COSY spectrum $(600 \mathrm{MHz})$ of 1 in DMSO- $d_{6}$.

Figure S5. HSQC spectrum $(600 \mathrm{MHz})$ of 1 in DMSO- $d_{6}$.

Figure S6. HMBC spectrum (600 MHz) of 1 in DMSO- $d_{6}$.

Figure S7. NOESY spectrum $(600 \mathrm{MHz})$ of 1 in DMSO- $d_{6}$.

Figure S8. 1D NOESY spectrum $(600 \mathrm{MHz})$ of 1 in DMSO- $d_{6}$.

Figure S9. HR-ESI-MS spectrum of 2.

Figure S10. ${ }^{1} \mathrm{H}$ NMR spectrum $(600 \mathrm{MHz})$ of 2 in DMSO- $d_{6}$.

Figure S11. HR-ESI-MS spectrum of $\mathbf{3}$.

Figure S12. ${ }^{1} \mathrm{H}$ NMR spectrum $(600 \mathrm{MHz})$ of 3 in DMSO- $d_{6}$.

Figure S13. ${ }^{13} \mathrm{C}$ NMR spectrum $(150 \mathrm{MHz})$ of 3 in DMSO- $d_{6}$.

Figure S14. COSY spectrum (600 MHz) of 3 in DMSO- $d_{6}$.

Figure S15. HSQC spectrum (600 MHz) of 3 in DMSO- $d_{6}$.

Figure S16. HMBC spectrum $(600 \mathrm{MHz})$ of 3 in DMSO- $d_{6}$.

Figure S17. NOESY spectrum $(600 \mathrm{MHz})$ of 3 in DMSO- $d_{6}$.

Figure S18. Key 2D correlation of loongmycinC (3).

Figure S19. PCR verification for gene mutants.

Figure S20. LC-MS analysis for heterologous production of loonamycin C (3).

Reference 


\section{Experimental Procedures}

General.

All 1D and 2D NMR spectra were recorded on a Bruker Avance 600 at $600 \mathrm{MHz}$ for ${ }^{1} \mathrm{H}$ and $150 \mathrm{MHz}$ for ${ }^{13} \mathrm{C}$ nuclei. UV-vis spectra were recorded on a Nanodrop 2000 spectrometer with a $10 \mathrm{~mm}$ cuvette. Optical rotation value was measured on a Rudolph Autopol IV automatic polarimeter. High resolution mass data were obtained on an Agilent 6530 TOF LC/MS spectrometer. Semipreparative RP-HPLC was performed on an Agilent 1260 HPLC with an Agilent Eclipse XDB-C18 column $(5 \mu, 250 \times 9.4 \mathrm{~mm})$. All chemicals used in the study were of analytical grade. The enzymes for PCR were purchased form Vazyme.

Strain isolation and identification. NA01583 strain was obtained from the marine sediment, which was collected at the coast near Hainan island in 2016. It was identified as Nocardiopsis flavescens based on its 16S rRNA gene sequence (accession number: MT371575).

Bacterial strains, plasmids and culture conditions. E. coli strains EPI300 and ET12567/pUZ8002 were grown on solid or in liquid LB medium at $37^{\circ} \mathrm{C}$. pJTU2554 was used as the cosmid vector. $N$. flavescens sp. NA01583 was cultured in TSB for 2 days at $28{ }^{\circ} \mathrm{C}$ for isolation of total DNA. $N$. flavescens NA01583 and S. lividans K4-114 were grown on MS medium for sporulation.

Fermentation and extraction. $N$. flavescens sp. NA015831, S. lividans K4-114/pJTU2554, and S. lividans K4-114/31P9 was cultured in MS plate for sporulation. Then, the strains were transferred on IPS2 medium with supplement of $4 \mathrm{~g} / \mathrm{L} \mathrm{NaCl}$ or $\mathrm{NaBr}$. After growing at $28{ }^{\circ} \mathrm{C}$ for 7 days, the medium was air dried and extracted by methanol for three times, and the resulting extract was concentrated to yield solid material by rotary evaporation.

Isolation of loonamycins A-C (1-3). The crude extract (2.2 g) obtained from supplement of NaCl was fractionated by MPLC over ODS column eluted with a linear gradient $\mathrm{MeOH}-\mathrm{H}_{2} \mathrm{O}$ system from $10 \% \mathrm{MeOH}$ to $100 \% \mathrm{MeOH}$ to give fifteen fractions. The fractions were subjected for LC-MS analysis. Those showing chlorinated compound signals were combined and concentrated, and further fractionated by Sephadex LH-20 column using MeOH to give several fractions. Once again, the targeted fraction was purified by semi-HPLC with $35 \% \mathrm{MeOH}$ in $0.1 \% \mathrm{TFA} /$ water system with $2.0 \mathrm{~mL} / \mathrm{min}$ flow rate to give 1 (3.4 mg, $\left.t_{R}: 22.1 \mathrm{~min}\right)$ and $\mathbf{2}\left(0.4 \mathrm{mg}, t_{R}: 21.1 \mathrm{~min}\right)$. Similarly, $3\left(1.8 \mathrm{mg}, t_{R}: 22.3 \mathrm{~min}\right)$ was obtained from the crude extract (1.9 g) supplemented with $\mathrm{NH}_{4} \mathrm{Br}$.

Construction of Cosmid library. The cosmid library of $N$. flavescens sp. NA01583 was constructed using an established protocol. For the generation of a cosmid library, high quality chromosomal DNA (>150 kb) was isolated by salting-out procedure and partially digested with MboI, dephosphorylated with Alkaline Phosphatase (Thermo), and size-fractionated in low-melting temperature agarose by using pulsed-field gel electrophoresis (PFGE). The recovered DNA was ligated with linearized cosmid vector pJTU2554 in a 2.5:1 molar ratio. After an overnight ligation at $16{ }^{\circ} \mathrm{C}$, the mixture was packaged using MaxPlaxTM Lambda Packaging Extracts and transfected into E. coli EPI300 cell. The apramycin resistant colonies were picked individually and inoculated in LB $(100 \mu \mathrm{L})$ that was supplied with apramycin in each well of 96-well plates. These plates were grown at $37^{\circ} \mathrm{C}$ for $20 \mathrm{~h}$, and then $50 \%$ glycerol $(100 \mu \mathrm{L})$ was added into each well for storage at $-80^{\circ} \mathrm{C}$. Finally, the cosmid library of $N$. flavescens sp. NA01583 consisted of 12, 288 colonies with an average insert size of $40 \mathrm{~kb}$. The desired cosmid was screened by two pairs of primers listed in Table S5.

Heterologous Expression and LC/MS detection. The cosmids were introduced into heterologous Streptomyces by conjugation from E. coli ET12567/pUZ8002 according to the literature procedure. ${ }^{1}$ Fermentation was carried out as described above and the crude extracts were dissolved in $1 \mathrm{ml}$ methanol and used for LC/MS analysis. Each sample $(10 \mu \mathrm{L})$ was injected into the column and first eluted with a linear gradient of $30 \%$ methanol in water to $100 \%$ methanol for 6 min, and finally with $100 \%$ methanol for $3 \mathrm{~min}$ at a flow rate of $0.4 \mathrm{~mL} / \mathrm{min}$. 


\section{Construction of gene knock-out mutants.}

The gene knock out was achieved by using pKOV and pDF25 plasmids in E. coli as described in literature ${ }^{1}$. For looM2 and looS10, the gene knock out mutants were constructed by PCR-targeting with the primers listed in Table S5.

Cytotoxicity assay. Human cancer cell lines SH-SY5Y, SUM1315, Hela and HCC78 were purchased from the Shanghai Institute of Cell Biology (Shanghai, China). Human colon carcinoma cell lines HT29, SW620, HCT116 and human liposarcoma cell line SW872 cells were purchased from the American Type Culture Collection (Rockville, MD). All the cells were maintained in DMEM (Life Technologies, Grand island, NY) supplemented with 10\% fetal bovine serum (FBS, Life Technologies), $100 \mathrm{U} / \mathrm{ml}$ penicillin, and $100 \mathrm{mg} / \mathrm{ml}$ streptomycin. $2 \times 10^{4}$ cells were seeded into 96 -well plates, and incubated with various concentrations of compound 1 for 72 hours. In total, $20 \mu$ of MTT ( $4 \mathrm{mg} / \mathrm{mL}$ in PBS) was added per well $4 \mathrm{~h}$ before the end of the incubation. MTT formazan production was dissolved by DMSO replacing the medium. The optical density at $570 \mathrm{~nm}$ was measured using a FL × 800 Fluorescence Microplate Reader (BioTek, Winooski, VT).

\section{Physical data for compounds 1-3}

Loonamycin A (1), orange amorphous powder, $[\alpha]_{\mathrm{D}}{ }^{20}=-17.7(c=0.26, \mathrm{MeOH}) ; \mathrm{UV}(\mathrm{MeOH}): \lambda \max (\log \varepsilon)=248(4.17), 300$ (4.02), 314 (4.04), 340 (3.7), 421(3.07); HR-ESI-MS: $m / z$ : calcd for $\mathrm{C}_{35} \mathrm{H}_{36} \mathrm{Cl}_{2} \mathrm{~N}_{4} \mathrm{O}_{11} \mathrm{H}^{+}$: 759.1830 ; found: 759.1830 [M+H] . ${ }^{1} \mathrm{H}$ and ${ }^{13} \mathrm{C}$ NMR data, see Table $\mathrm{S} 1$.

Loonamycin B (2), orange amorphous powder, HR-ESI-MS: $m / z$ : calcd for $\mathrm{C}_{34} \mathrm{H}_{34} \mathrm{Cl}_{2} \mathrm{~N}_{4} \mathrm{O}_{11} \mathrm{H}^{+}$: 745.1674; found: 745.1676 $[\mathrm{M}+\mathrm{H}]^{+} .{ }^{1} \mathrm{H}$ NMR data, see Table S2.

Loonamycin C (3), orange amorphous powder, $[\alpha]_{\mathrm{D}}{ }^{20}=-13.3(c=0.015, \mathrm{MeOH})$; UV(MeOH): $\lambda \max (\log \varepsilon)=248(4.22), 300$ (4.10), 314 (4.13), 340 (3.80), 421(3.17); HR-ESI-MS: $m / z$ : calcd for $\mathrm{C}_{35} \mathrm{H}_{36} \mathrm{Br}_{2} \mathrm{~N}_{4} \mathrm{O}_{11} \mathrm{H}^{+}$: 847.0820 ; found: 847.0819 [M+H] ${ }^{1} \mathrm{H}$ and ${ }^{13} \mathrm{C}$ NMR data, see Table S3. 
Table S1. ${ }^{1} \mathrm{H}(600 \mathrm{MHz})$ and ${ }^{13} \mathrm{C}(150 \mathrm{MHz})$ NMR data of $\mathbf{1}$ in DMSO- $d_{6}$.

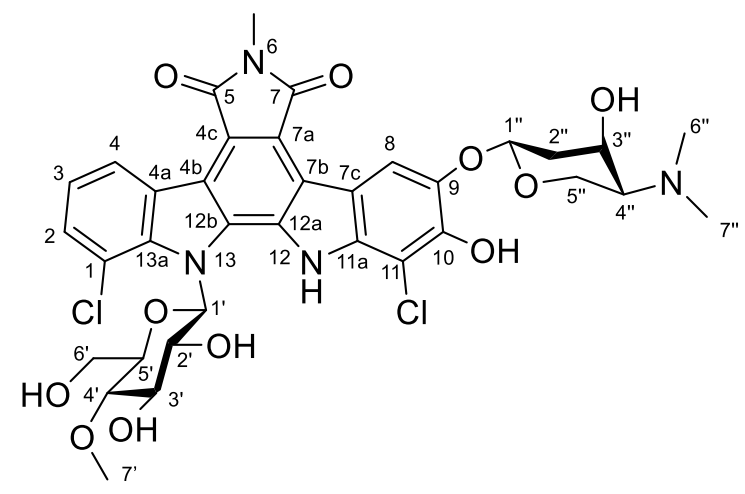

\begin{tabular}{|c|c|c|c|c|c|}
\hline No. & $\delta_{\mathrm{c}}$, Type & $\delta_{\mathrm{H}}(J$ in $\mathrm{Hz})$ & No. & $\delta_{\mathrm{c}}$, Type & $\delta_{\mathrm{H}}(J$ in $\mathrm{Hz})$ \\
\hline 1 & $104.1, \mathrm{C}$ & & $1 '$ & $85.1, \mathrm{CH}$ & $6.82, \mathrm{~d}(9.0)$ \\
\hline 2 & $130.9, \mathrm{CH}$ & 7.73, d (7.9) & 2 & $72.5, \mathrm{CH}$ & $3.59, \mathrm{t}(9.0)$ \\
\hline 3 & 123.6, CH & 7.47, t (7.9) & $3^{\prime}$ & $78.0, \mathrm{CH}$ & $3.50, \mathrm{~m}$ \\
\hline 4 & $124.5, \mathrm{CH}$ & $9.22, \mathrm{~d}(7.9)$ & 4 ' & $80.2, \mathrm{CH}$ & $3.47, \mathrm{t}(9.2)$ \\
\hline $4 a$ & $125.3, \mathrm{C}$ & & 5 , & $84.5, \mathrm{CH}$ & $3.83, \mathrm{dt}(9.2,4.1)$ \\
\hline $4 b$ & 117.1, C & & 6 ' & $60.9, \mathrm{CH}_{2}$ & 3.96, brs \\
\hline $4 \mathrm{c}$ & $120.2, \mathrm{C}$ & & 7 & $60.6, \mathrm{CH}_{3}$ & $3.55, \mathrm{~s}$ \\
\hline 5 & 173.9, C & & $1 "$ & $99.5, \mathrm{CH}$ & $5.36, \mathrm{dd}(8.0,2.3)$ \\
\hline 6 & $24.8, \mathrm{CH}_{3}$ & $3.22, \mathrm{~s}$ & $2^{\prime \prime}$ & $37.7, \mathrm{CH}_{2}$ & $1.83, \mathrm{ddd},(12.9,8.0,2.9)$ \\
\hline 7 & $168.8, \mathrm{C}$ & & & & $2.22, \mathrm{~m}$ \\
\hline $7 \mathrm{a}$ & $120.2, \mathrm{C}$ & & $3 "$ & $64.5, \mathrm{CH}$ & $4.25, \mathrm{dt}(5.8,3.0)$ \\
\hline $7 b$ & 119.6, C & & $4 "$ & $63.6, \mathrm{CH}$ & $2.22, \mathrm{~m}$ \\
\hline $7 \mathrm{c}$ & $130.5, \mathrm{C}$ & & $5 "$ & $62.4, \mathrm{CH}_{2}$ & 3.67, dd $(11.4,9.2)$ \\
\hline 8 & $123.0, \mathrm{CH}$ & $7.46, \mathrm{~s}$ & & & $3.92, \mathrm{dd}(11.4,4.0)$ \\
\hline 9 & 139.2, C & & $6 "$ & $43.7, \mathrm{CH}_{3}$ & $2.27, \mathrm{~s}$ \\
\hline 10 & 144.3, C & & $7^{\prime \prime}$ & $43.7, \mathrm{CH}_{3}$ & $2.27, \mathrm{~s}$ \\
\hline 11 & $112.4, \mathrm{C}$ & & $10-\mathrm{OH}$ & & 12.80, brs \\
\hline $11 \mathrm{a}$ & $135.5, \mathrm{C}$ & & $12-\mathrm{NH}$ & & 10.70, brs \\
\hline $12 \mathrm{a}$ & 115.3, C & & 2'-OH & & 5.04 , brs \\
\hline $12 b$ & $130.7, \mathrm{C}$ & & 3'-OH & & 5.38, brs \\
\hline $13 \mathrm{a}$ & $139.1, \mathrm{C}$ & & $6^{\prime}-\mathrm{OH}$ & & 5.22, brs \\
\hline
\end{tabular}


Table S2. ${ }^{1} \mathrm{H}(600 \mathrm{MHz})$ NMR data of 2 in DMSO- $d_{6}$.

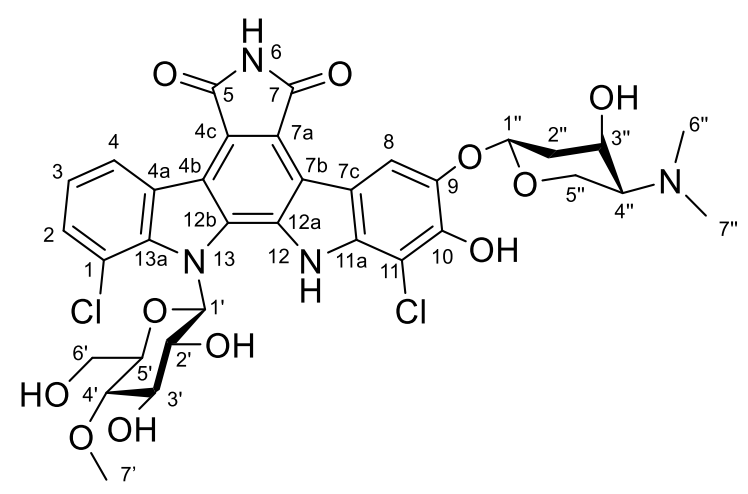

\begin{tabular}{|c|c|c|c|}
\hline No. & $\delta_{\mathrm{H}}(J$ in $\mathrm{Hz})$ & No. & $\delta_{\mathrm{H}}(J$ in $\mathrm{Hz})$ \\
\hline 2 & $7.74, \mathrm{dd}(7.9,1.2)$ & $1 "$ & $5.44, \mathrm{dd}(2.4,6.6)$ \\
\hline 3 & $7.48, \mathrm{t}(7.9)$ & $2 "$ & $2.03, \mathrm{~m}$ \\
\hline 4 & $9.24, \mathrm{dd}(7.9,1.2)$ & & $2.31, \mathrm{~m}$ \\
\hline \multirow[t]{2}{*}{8} & $7.53, \mathrm{~s}$ & $3 "$ & 4.26 , dd $(11.9,3.2)$ \\
\hline & & $4 "$ & $3.45, \mathrm{~m}$ \\
\hline 1 ' & $6.84, \mathrm{~d}(9.2)$ & $5^{\prime \prime}$ & $3.82, \mathrm{~m}$ \\
\hline $2^{\prime}$ & $3.59, \mathrm{~m}$ & & $3.97, \mathrm{~m}$ \\
\hline 3' & $3.52, \mathrm{~m}$ & $6 "$ & $2.82, \mathrm{~s}$ \\
\hline 4 ' & $3.49, \mathrm{~m}$ & $7 "$ & $2.89, \mathrm{~s}$ \\
\hline 5 , & $3.84, \mathrm{dd}(9.6,5.0)$ & 6-NH & $12.01, \mathrm{~s}$ \\
\hline 6 ' & $3.97, \mathrm{~m}$ & $10-\mathrm{OH}$ & $12.96, \mathrm{~s}$ \\
\hline \multirow[t]{2}{*}{7} & $3.55, \mathrm{~s}$ & $12-\mathrm{NH}$ & $10.73, \mathrm{~s}$ \\
\hline & & 6'-OH & $5.24, \mathrm{t}(5.6)$ \\
\hline
\end{tabular}


Table S3. ${ }^{1} \mathrm{H}(600 \mathrm{MHz})$ and ${ }^{13} \mathrm{C}(150 \mathrm{MHz})$ data of 3 in DMSO- $d_{6} .{ }^{\mathrm{a}}$

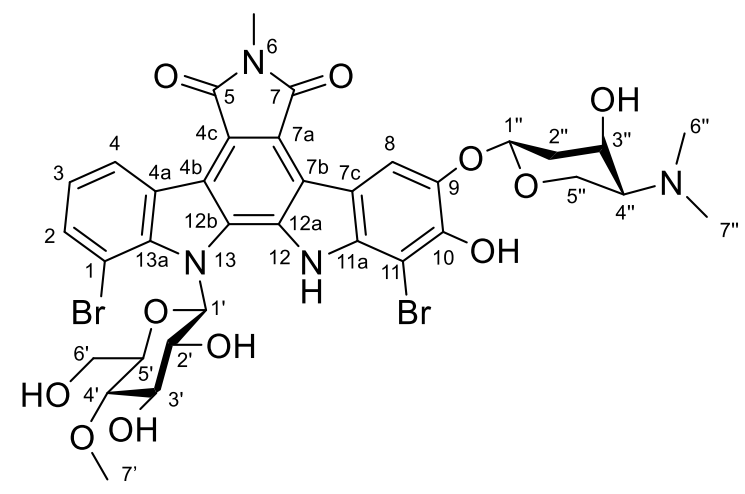

\begin{tabular}{|c|c|c|c|c|c|}
\hline No. & $\delta$ c, Туре & $\delta_{\mathrm{H}}(J$ in $\mathrm{Hz})$ & No. & $\delta$ с, Туре & $\delta_{\mathrm{H}}(J$ in $\mathrm{Hz})$ \\
\hline 1 & $105.2, \mathrm{C}$ & & 1 ' & $84.6, \mathrm{CH}$ & $6.81, \mathrm{~d}(8.8)$ \\
\hline 2 & $134.2, \mathrm{CH}$ & $7.88, \mathrm{~d}(7.9)$ & 2 & $72.3, \mathrm{CH}$ & $3.51, \mathrm{t}(8.8)$ \\
\hline 3 & $124.1, \mathrm{CH}$ & $7.38, \mathrm{t}(7.9)$ & 3 , & $78.3, \mathrm{CH}$ & $3.47, \mathrm{~m}$ \\
\hline 4 & $124.9, \mathrm{CH}$ & $9.17, \mathrm{~d}(7.9)$ & 4, & $80.6, \mathrm{CH}$ & $3.45, \mathrm{~m}$ \\
\hline $4 a$ & $125.4, \mathrm{C}$ & & 5 , & $82.2, \mathrm{CH}$ & $3.84, \mathrm{~m}$ \\
\hline $4 \mathrm{~b}$ & 119.6, C & & 6 ' & $59.0, \mathrm{CH}_{2}$ & $3.88,4.26, \mathrm{~m}$ \\
\hline $4 c$ & $120.3, \mathrm{C}$ & & 7 & $60.6, \mathrm{CH}_{3}$ & $3.54, \mathrm{~s}$ \\
\hline 5 & 173.9, C & & $1 "$ & $99.1, \mathrm{CH}$ & $5.42, \mathrm{~m}$ \\
\hline 6 & $24.8, \mathrm{CH}_{3}$ & $3.20, \mathrm{~s}$ & $2^{\prime \prime}$ & $36.8, \mathrm{CH}_{2}$ & $2.02, \mathrm{~m}$ \\
\hline 7 & 168.7, C & & & & $2.31, \mathrm{~m}$ \\
\hline $7 \mathrm{a}$ & 120.1, C & & $3 "$ & $62.1, \mathrm{CH}$ & 4.51 , brs \\
\hline $7 b$ & $91.3, \mathrm{C}$ & & $4 "$ & $62.8, \mathrm{CH}$ & $3.43, \mathrm{~m}$ \\
\hline $7 \mathrm{c}$ & $130.4, \mathrm{C}$ & & $5^{\prime \prime}$ & $61.5, \mathrm{CH}_{2}$ & $4.01, \mathrm{~m}$ \\
\hline 8 & $125.8, \mathrm{CH}$ & $7.59, \mathrm{~s}$ & & & $4.10, \mathrm{~m}$ \\
\hline 9 & 139.0, C & & $6 "$ & $42.6, \mathrm{CH}_{3}$ & $2.85, \mathrm{~s}$ \\
\hline 10 & 144.9, C & & $7^{\prime \prime}$ & $42.6, \mathrm{CH}_{3}$ & $2.85, \mathrm{~s}$ \\
\hline 11 & $112.4, \mathrm{C}$ & & $10-\mathrm{OH}$ & & $12.89, \mathrm{~s}$ \\
\hline $11 \mathrm{a}$ & 137.1, C & & $12-\mathrm{NH}$ & & $10.50, \mathrm{~s}$ \\
\hline $12 \mathrm{a}$ & 115.3, C & & $2^{\prime}-\mathrm{OH}$ & & 4.92 , brs \\
\hline $12 b$ & $131.0, \mathrm{C}$ & & $3^{\prime}-\mathrm{OH}$ & & 5.42 , brs \\
\hline $13 a$ & $140.9, \mathrm{C}$ & & $6^{\prime}-\mathrm{OH}$ & & $5.17, \mathrm{brs}$ \\
\hline
\end{tabular}


Table S4. Deduced functions of the genes within the loo cluster ${ }^{\text {a }}$

\begin{tabular}{|c|c|c|c|c|}
\hline Gene & Size $^{b}$ & Proposed function & homolog $^{c}$ & identity/similarity \\
\hline orf-2 & 151 & nucleotide pyrophosphohydrolase & $\overline{\text { AFU00128.1 }}$ & $63 / 76$ \\
\hline orf -1 & 333 & Hypothetical protein & WP_019630188.1 & $45 / 62$ \\
\hline $\mathrm{looH}$ & 530 & tryptophan halogenase & RebH, BAC15758.1 & $71 / 83$ \\
\hline $\operatorname{looU}$ & 482 & $\mathrm{Na}+/ \mathrm{H}+$ antiporter & RebU, BAC15757.1 & $34 / 50$ \\
\hline looG1 & 401 & O-glycosyltransferase & AtmG1, ABC02788.1 & $47 / 63$ \\
\hline looM2 & 228 & SAM-dependent methyltransferase & WP_084723458.1 & $47 / 66$ \\
\hline loos10 & 245 & putative aminomethylase & AtmS10, ABC02787.1 & $54 / 72$ \\
\hline looS13 & 366 & putative aminotransferase & TmlJ, ABL74960.1 & $67 / 80$ \\
\hline loos12 & 328 & putative dTDP-4-keto-6-deoxy-L-hexose 2,3-reductase & AtmS12, ABC02798.1 & $63 / 72$ \\
\hline $\operatorname{looS} 8$ & 433 & putative UDP-N-acetyl-D-mannosaminuronic acid dehydrogenase & AtmS8, ABC02801.1 & $56 / 68$ \\
\hline $\operatorname{loos} 9$ & 329 & putative UDP-glucose 4-epimerase & AtmS9, ABC02802.1 & $54 / 68$ \\
\hline looF & 175 & flavin reductase & RebF, BAC15756.1 & $58 / 68$ \\
\hline$l o o R$ & 939 & putative regulatory protein & AtmR, ABC02804.1 & $33 / 47$ \\
\hline looP & 355 & cytochrome $\mathrm{P} 450$ & AtmP, ABC02792.1 & $54 / 63$ \\
\hline looM & 262 & D-glucose O-methyltransferase & RebM, BAC15754.1 & $56 / 69$ \\
\hline orfA & 178 & SWIM zinc finger protein & RDI62709.1 & $37 / 52$ \\
\hline $\operatorname{orf} B$ & 629 & Superfamily II DNA or RNA helicase & ALL79985.1 & $52 / 63$ \\
\hline looR1 & 328 & Putative DNA-binding transcriptional regulator YafY & VXB76272.1 & $49 / 60$ \\
\hline looT1 & 343 & ABC-type multidrug transport system, ATPase component & SJM68297.1 & $56 / 70$ \\
\hline looT2 & 268 & multidrug $\mathrm{ABC}$ transporter permease & WP_055854524.1 & $62 / 77$ \\
\hline looS14 & 442 & NDP-hexose-2,3-dehydratase & AtmS14, ABC02799.1 & $53 / 63$ \\
\hline $\operatorname{loos} 7$ & 354 & putative sugar activating enzyme & AtmS7, ABC02794.1 & $53 / 66$ \\
\hline looP1 & 396 & cytochrome P450 hydroxylase & VisD, BAB83674.1 & $45 / 61$ \\
\hline $\operatorname{looG}$ & 382 & $\mathrm{~N}$-glycosyl transferase & RebG, BAC15749.1 & $62 / 75$ \\
\hline looO & 477 & L-tryptophan oxidase & RebO, BAC15750.1 & $57 / 70$ \\
\hline$l o o D$ & 1079 & CCA synthetase & AtmD, BAC15751.1 & $56 / 66$ \\
\hline $\operatorname{loo} C$ & 536 & FAD-monooxygenase & AtmC, ABC02791.1 & $65 / 73$ \\
\hline$o r f+1$ & 691 & hypothetical protein & WP_068693659.1 & $40 / 55$ \\
\hline$o r f+2$ & 156 & DUF4913 domain-containing protein & WP_077688804.1 & $61 / 76$ \\
\hline
\end{tabular}

$\bar{a}$ The sequence has been deposited in GenBank with the accession number MT371051. ${ }^{b}$ Numbers are in amino acids. ${ }^{c}$ Given in numbers are NCBI accession numbers. 
Table S5. Primers used in this study ${ }^{\mathrm{a}}$.

\begin{tabular}{|c|c|}
\hline Name & Sequence \\
\hline Screen-UP-F & GTCATCGACCATCGCTTCT \\
\hline Screen-UP-R & ACTTCACCGACACCCAATC \\
\hline Screen-DN-F & GGTGTCCTCTTCTTGTGGTTC \\
\hline Screen-DN-R & AGACCGAATCCTACGTCTACTC \\
\hline$\triangle L o o P 1-U P-F$ & GCGGCCGTTACTAGTGGATCCTGTCGTATGCGTAGGGTTTCT \\
\hline$\triangle L o o P 1-U P-R$ & AGCATTCCGGTTTTCTTTGCA \\
\hline$\triangle L o o P 1-D N-F$ & TGCAAAGAAAACCGGAATGCTCAAGATCCGGTGTGAACT \\
\hline$\triangle L o o P 1-D N-R$ & CCGGTCGACTCTAGAGGATCCTGGAGTCCCACGATGAA \\
\hline$\triangle L o o G 1-U P-F$ & GCGGCCGTTACTAGTGGATCCGGTCATGAATGTGGTGAACAG \\
\hline$\Delta L o o G 1-U P-R$ & GTCGTTGACGTTCTCGGA \\
\hline$\triangle L o o G 1-D N-F$ & TCCGAGAACGTCAACGACCATGCTTTCCCCATCAAT \\
\hline$\Delta L o o G 1-D N-R$ & CCGGTCGACTCTAGAGGATCCACTTCCTCGACGGTTACA \\
\hline$\Delta$ LooM2-F & GTCCGCACGATCAGCGAGATCTCGCCGGAGGTATCGGTGTGCAGCTCACGGTAACTGAT \\
\hline$\Delta L o o M 2-R$ & GAACACGACAGTGTTCTCCATATCCTTTCTCTTGACGTCTGTAGGCTGGAGCTGCTTC \\
\hline$\Delta \operatorname{LooS} 10-F$ & ACGCATCCGACCAGGCTCCTGAAAGGTGGAAAGAATATGTGCAGCTCACGGTAACTGAT \\
\hline$\Delta L o o S 10-R$ & TTCTGTCTCGGCGTGCGGGTGGCGCGCTCGAGGTCAGTCTGTAGGCTGGAGCTGCTTC \\
\hline$\triangle L o o M-U P-F$ & GCGGCCGTTACTAGTGGATCCTGGATGCAGTTGGCGATGAC \\
\hline$\Delta L o o M-U P-R$ & GTCTGACCCGGCCACGAT \\
\hline$\triangle L o o M-D N-F$ & ATCGTGGCCGGGTCAGACCATGTTCCGGACATCGTG \\
\hline$\Delta L o o M-D N-R$ & CCGGTCGACTCTAGAGGATCCACTTCAGCCACCAGATCA \\
\hline$\triangle L o o P-U P-F$ & GCGGCCGTTACTAGTGGATCCGGTGTGGGTGTTGTGGTCTATC \\
\hline$\triangle L o o P-U P-R$ & AAGCGGAACTGAACCGGC \\
\hline$\triangle L o o P-D N-F$ & GCCGGTTCAGTTCCGCTTCATAGTGTGACCCCTTGT \\
\hline$\triangle L o o P-D N-R$ & CCGGTCGACTCTAGAGGATCCCTCAAGGTTCCTCGGTTAAG \\
\hline Screen- $\Delta$ LooG1-F & ACGCGTGGCTGATGGAGC \\
\hline Screen- $\Delta$ LooG1- $R$ & CTCGAGGAAGCCCGAAATTGTT \\
\hline Screen- $\triangle L o o M-F$ & GGTCGCTCAGGTCGGTAA \\
\hline Screen- $\triangle$ LooM- $R$ & GTTGGTCACATAGGACGACAAAG \\
\hline Screen- $\Delta$ LooS10-F & GGTGAACAACCTGGCGTT \\
\hline Screen- $\Delta$ LooS10-R & CCGTGGGCTGGAAGATATTG \\
\hline Screen- $\triangle L o o P-F$ & CAAAAAAGCACGGGTCGG \\
\hline Screen- $\triangle L o o P-R$ & GACCGAAGAGAAACACGAAGT \\
\hline Screen- $\Delta$ LooP1-F & TTTACTCGAGCGGCGATG \\
\hline Screen- $\triangle L o o P 2-R$ & TATCCGGTATACGAGCCCTAC \\
\hline Screen- $\Delta$ LooM2-F & AGAAACCTTGGGCCCTCG \\
\hline Screen- $\Delta$ LooM2-R & GAGAACTTCCTCGACGGTTACA \\
\hline
\end{tabular}

${ }^{a}$ The italic latter indicating the homologous sequence for ligation. 
Table S6. Cytotoxicity assay of $\mathbf{1}$.

\begin{tabular}{lll}
\hline Cell line & Cancer type & IC50 $(\mathrm{nM})$ \\
\hline SH-SY5Y & Neuroblastoma & 283.6 \\
SUM1315 & Breast cancer & 121.3 \\
HT29 & Colorectal cancer & 81.3 \\
SW620 & Colorectal cancer & 90.5 \\
HCT116 & Colorectal cancer & 31.4 \\
Hela & Cervical cancer & 100.1 \\
SW872 & Liposarcoma & 92.3 \\
HCC78 & Lung cancer & 41.5 \\
\hline
\end{tabular}




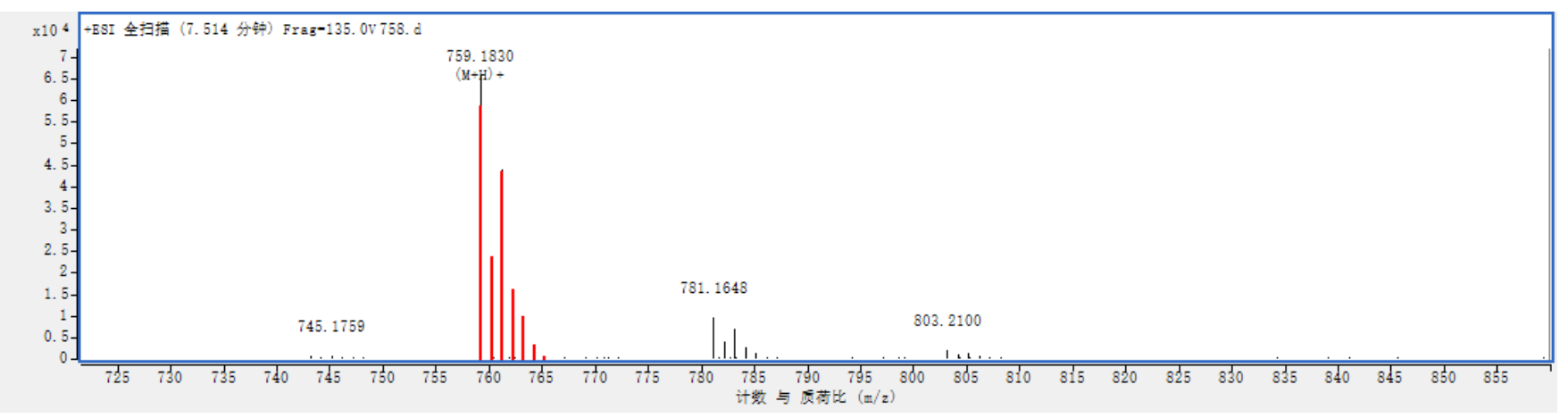

Figure S1. HR-ESI-MS spectrum of $\mathbf{1 .}$

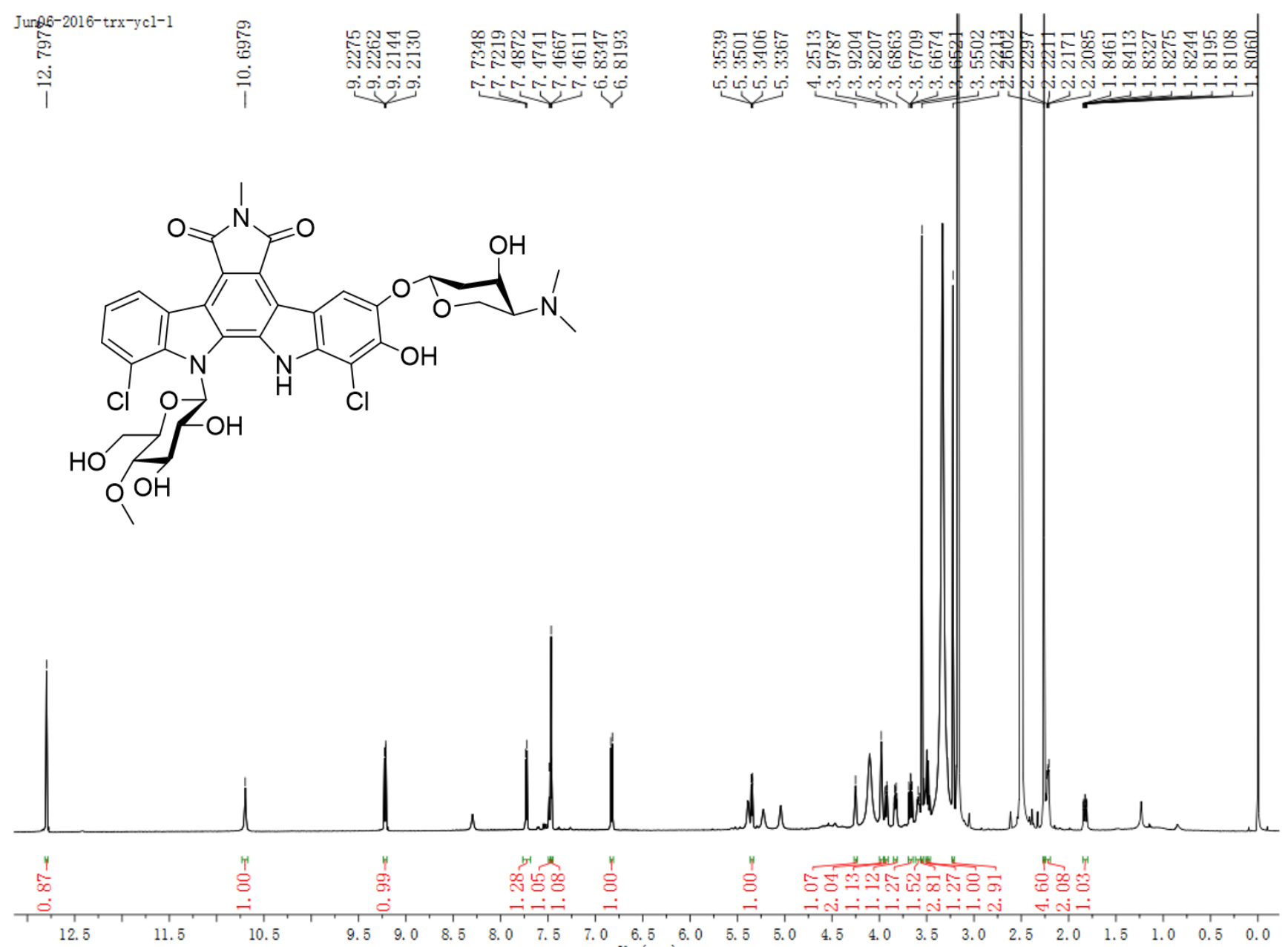

Figure S2. ${ }^{1} \mathrm{H}$ NMR spectrum $(600 \mathrm{MHz})$ of 1 in DMSO- $d_{6}$. 


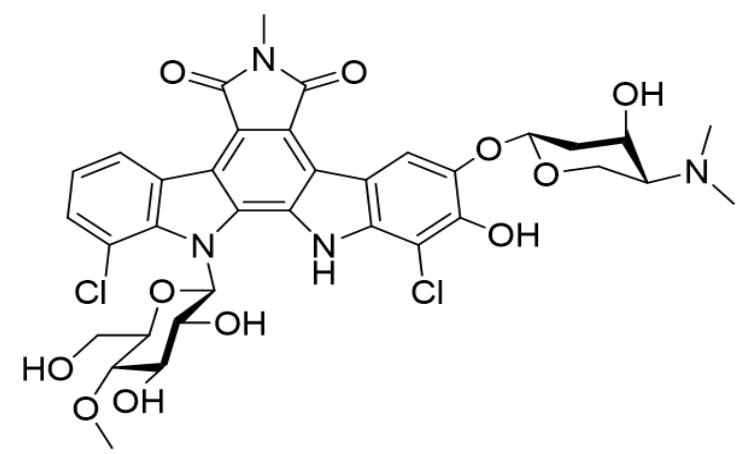

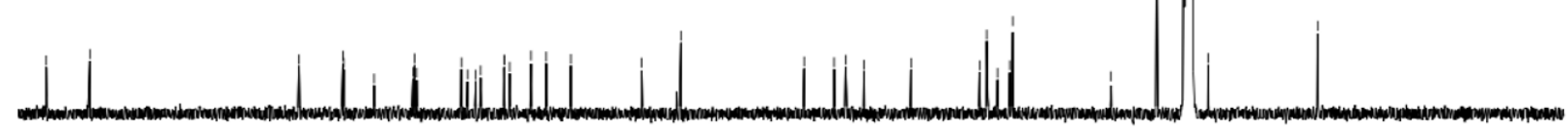

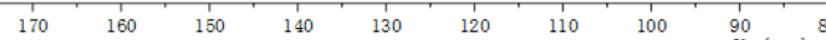

Figure S3. ${ }^{13} \mathrm{C}$ NMR spectrum $(150 \mathrm{M} \mathrm{Hz})$ of 1 in DMSO- $d_{6}$.

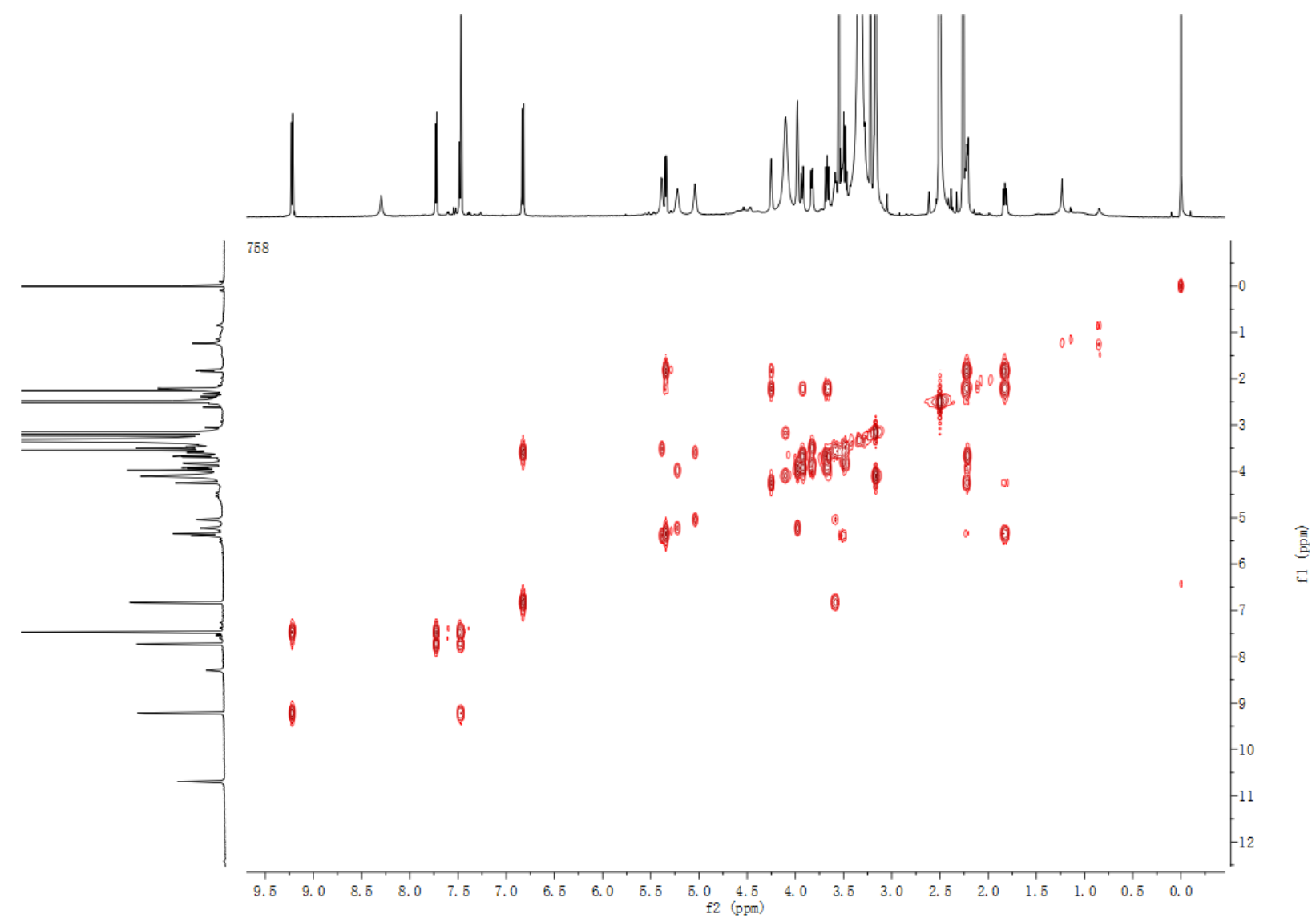

Figure S4. COSY spectrum $(600 \mathrm{MHz})$ of 1 in DMSO- $d_{6}$. 


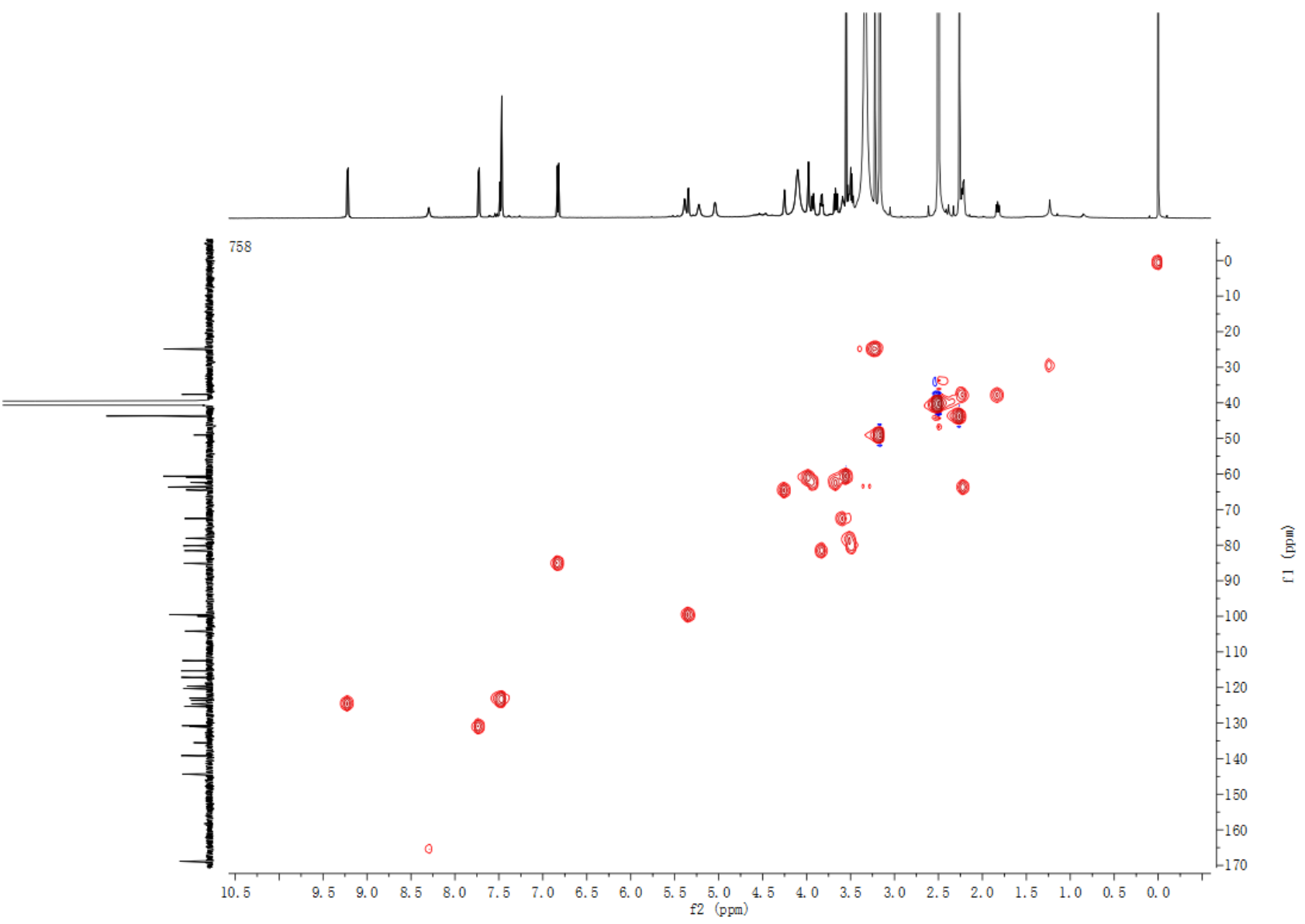

Figure S5. HSQC spectrum $(600 \mathrm{MHz})$ of 1 in DMSO- $d_{6}$.

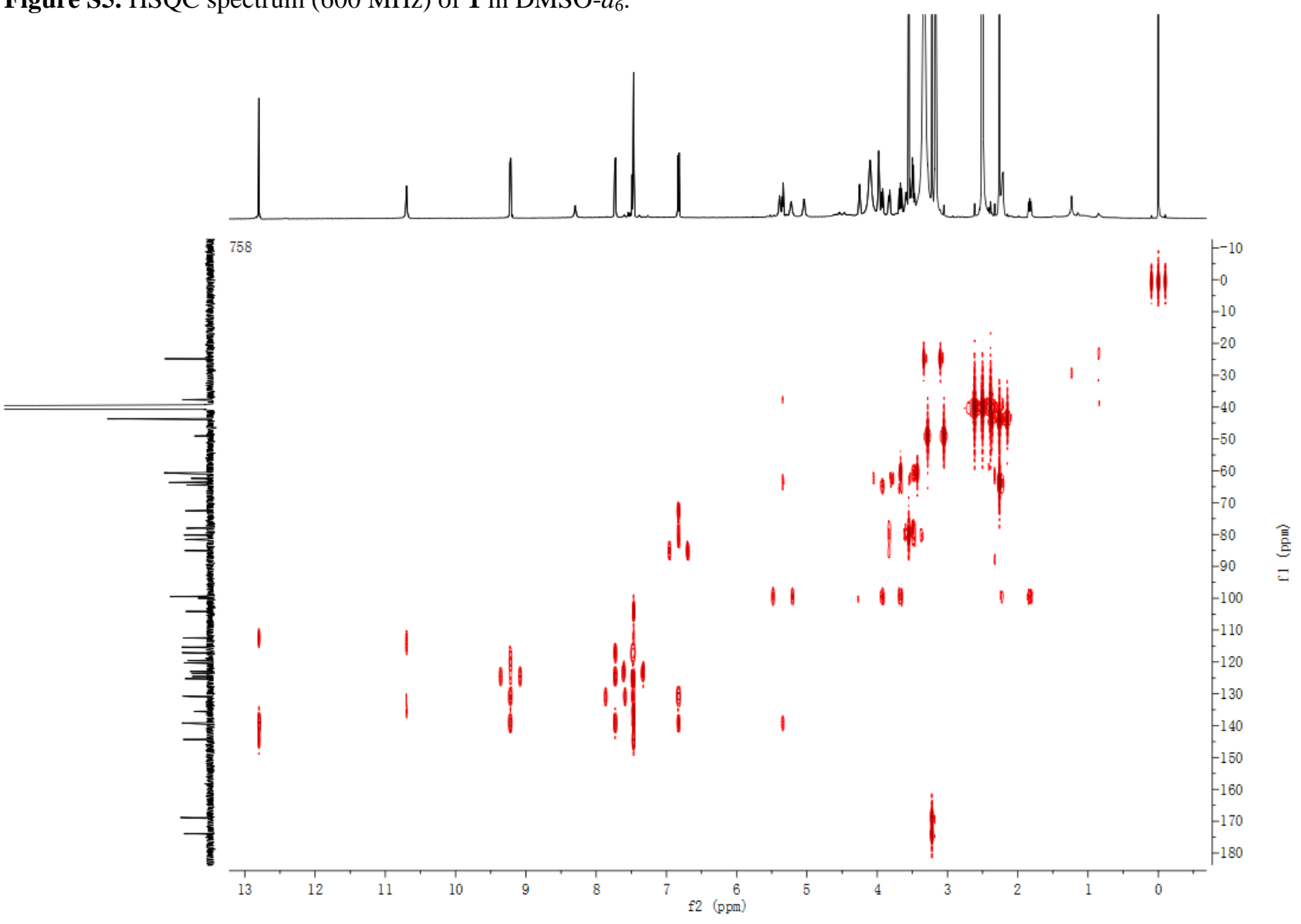

12 


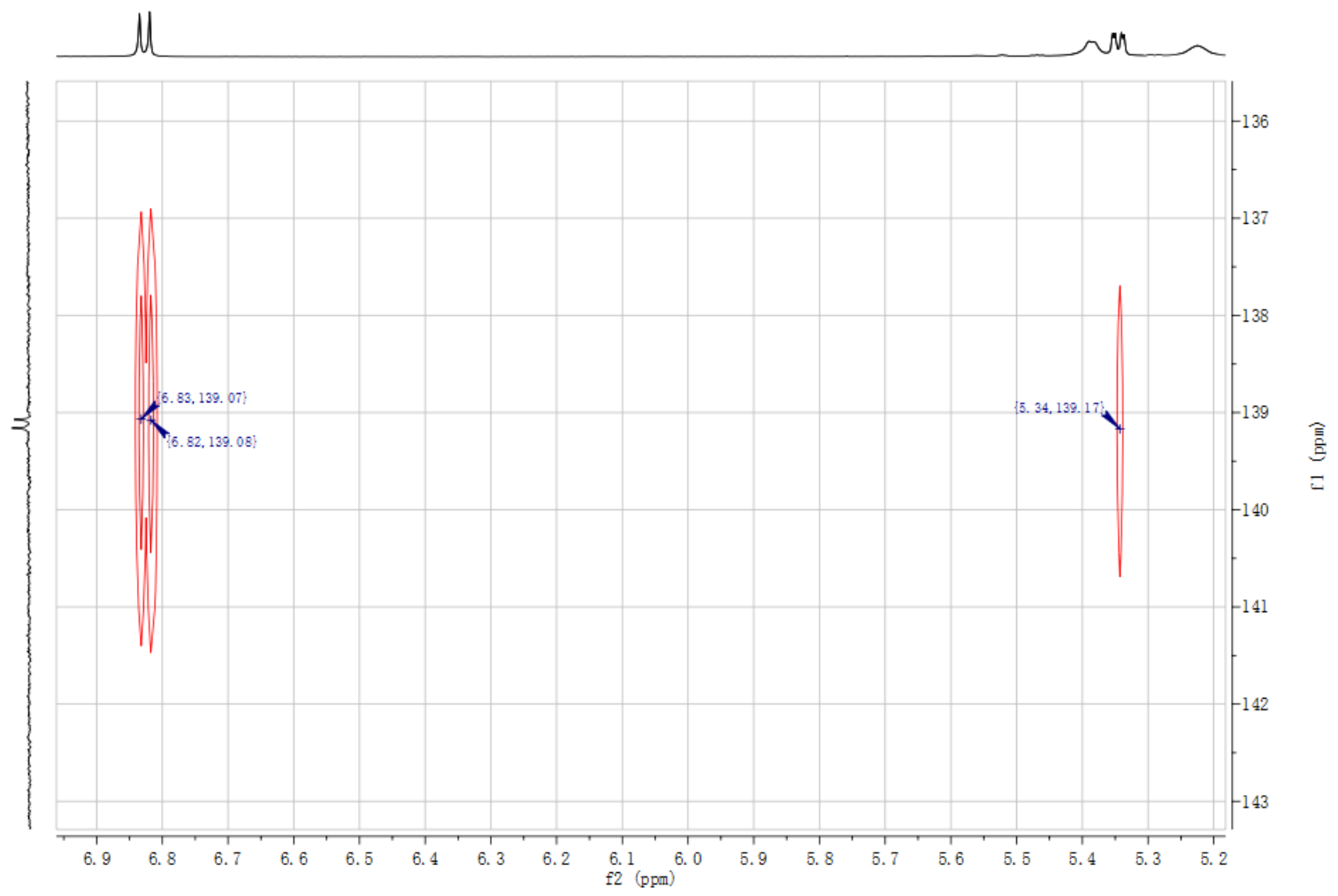

Figure S6. HMBC spectrum (600 MHz) of 1 in DMSO- $d_{6}$.

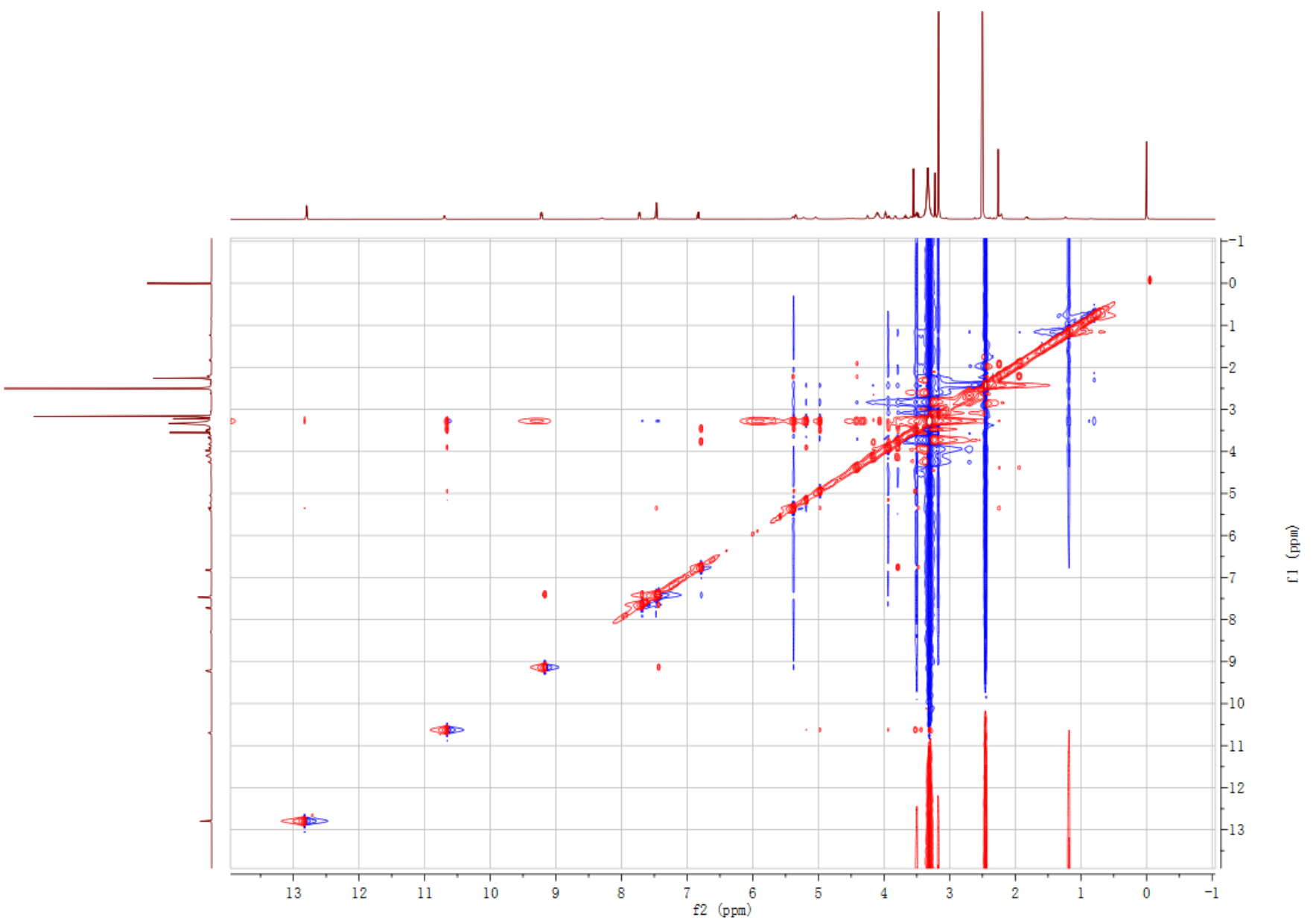




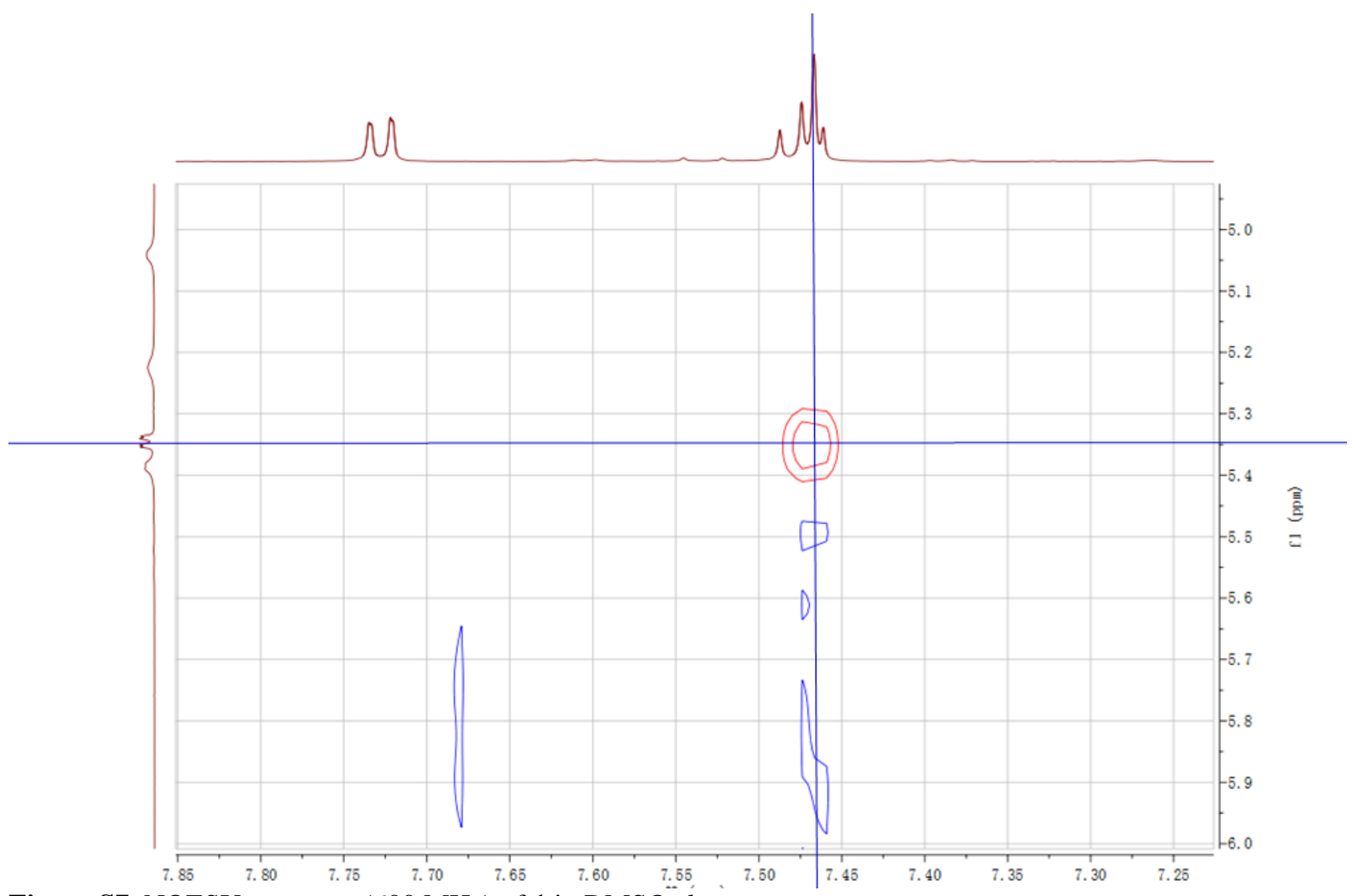

Figure S7. NOESY spectrum $(600 \mathrm{MHz})$ of 1 in DMSO- $d_{6}$.
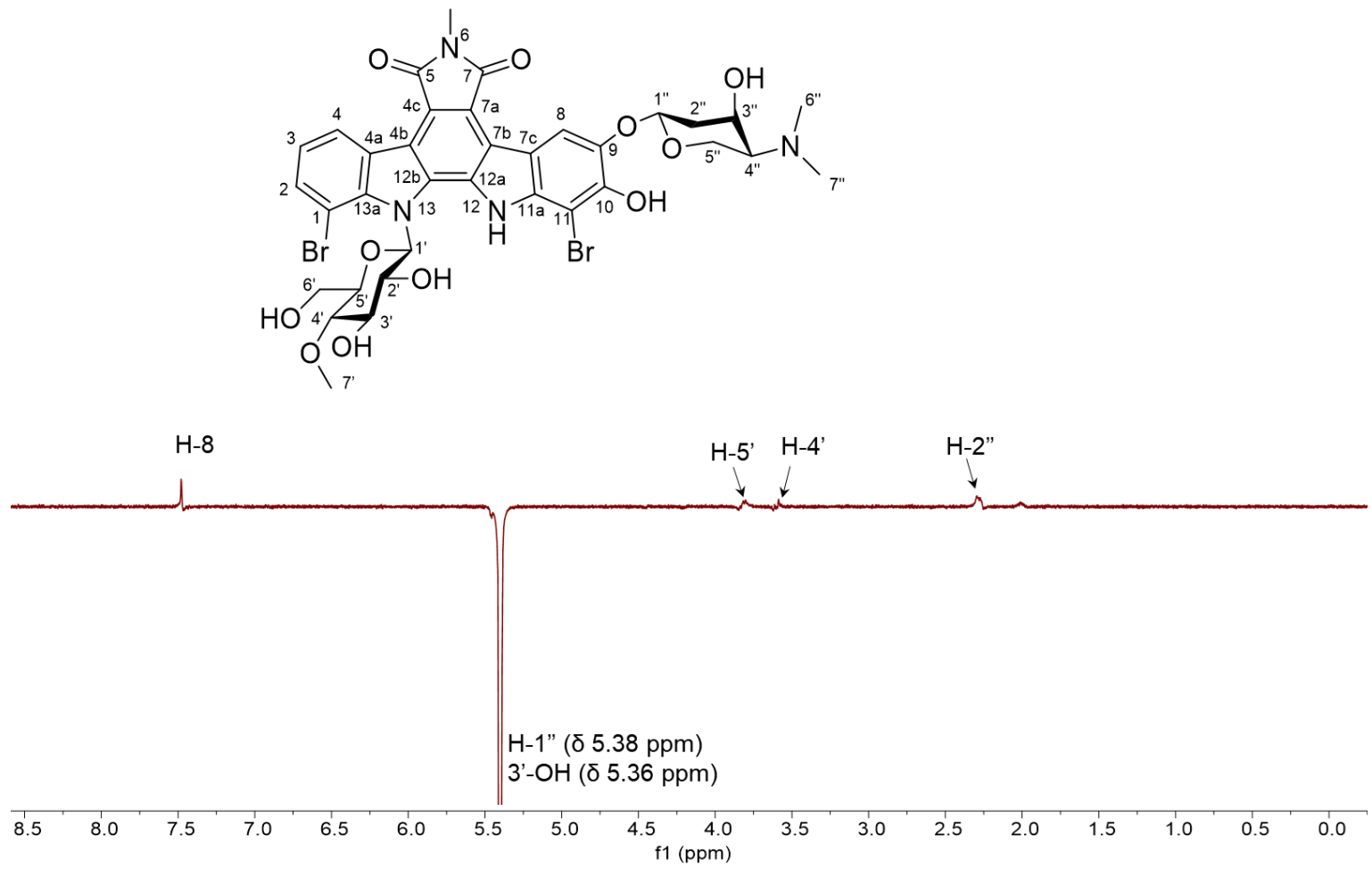

Figure S8. 1D NOE spectrum $(600 \mathrm{MHz})$ of 1 in DMSO- $d_{6}$. 


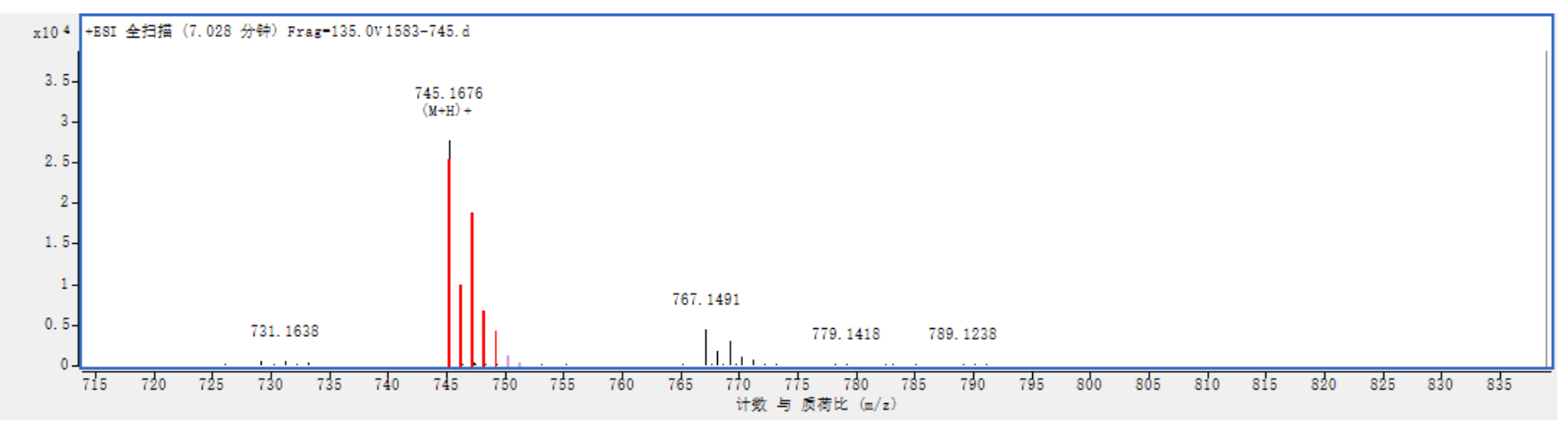

Figure S9. HR-ESI-MS spectrum of 2.

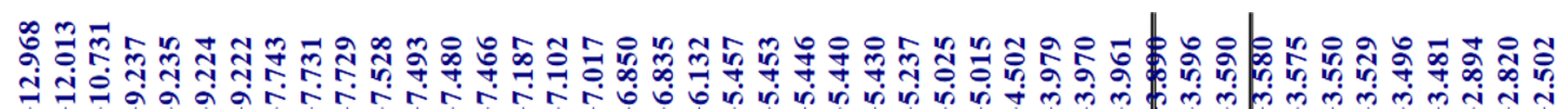<smiles>COCCOC(O)C(O)CO</smiles>

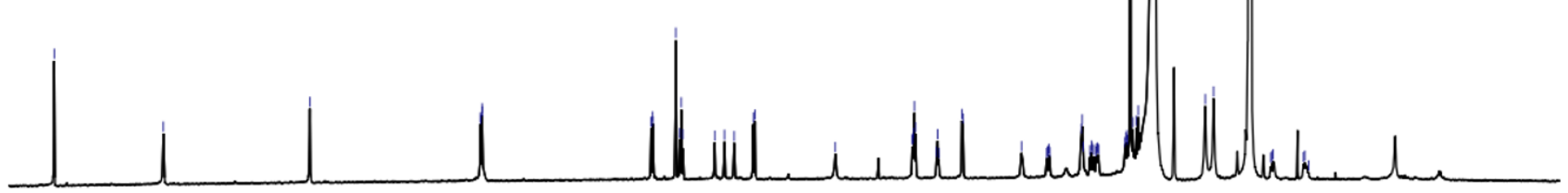

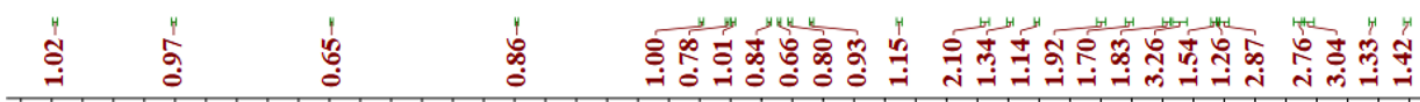

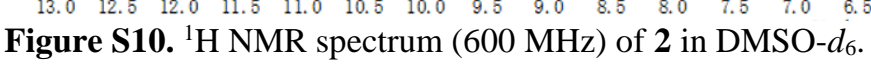




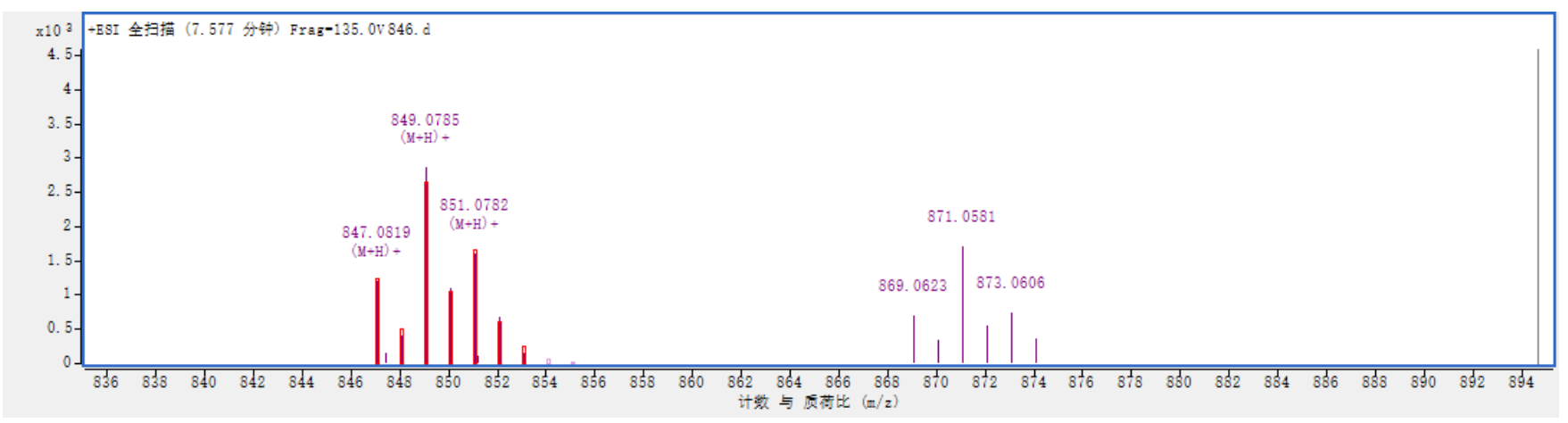

Figure S11. HR-ESI-MS spectrum of 3.

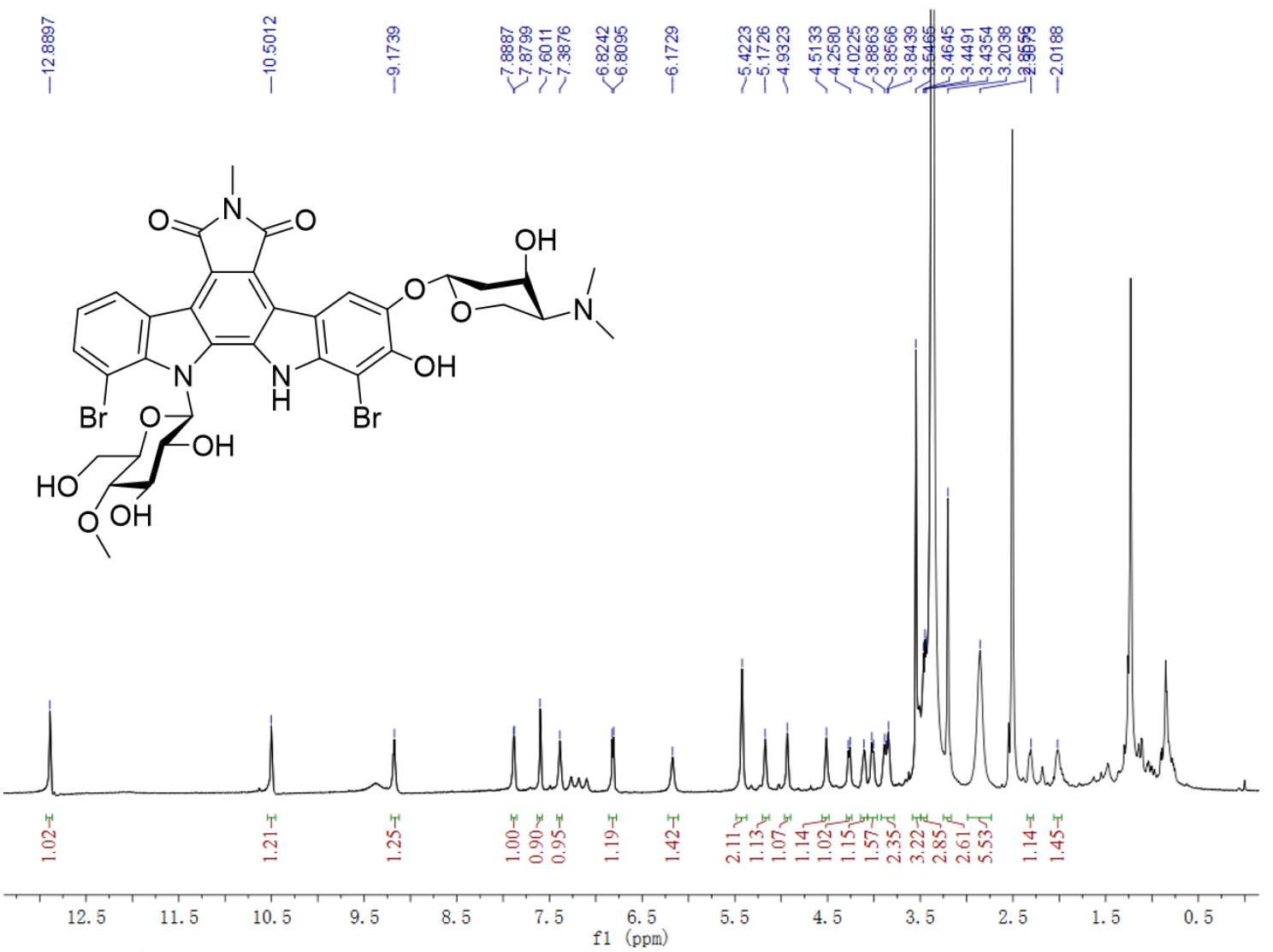

Figure S12. ${ }^{1} \mathrm{H}$ NMR spectrum $(600 \mathrm{MHz})$ of 3 in DMSO- $d_{6}$. 
<smiles>COCC(O)C(O)COC(O)C(O)CO</smiles>
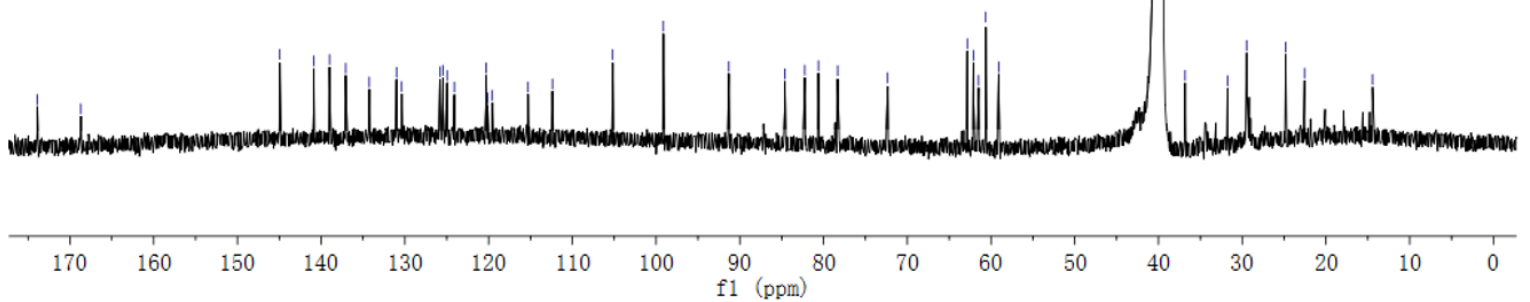

Figure S13. ${ }^{13} \mathrm{C}$ NMR spectrum $(150 \mathrm{M} \mathrm{Hz})$ of 3 in DMSO- $d_{6}$.

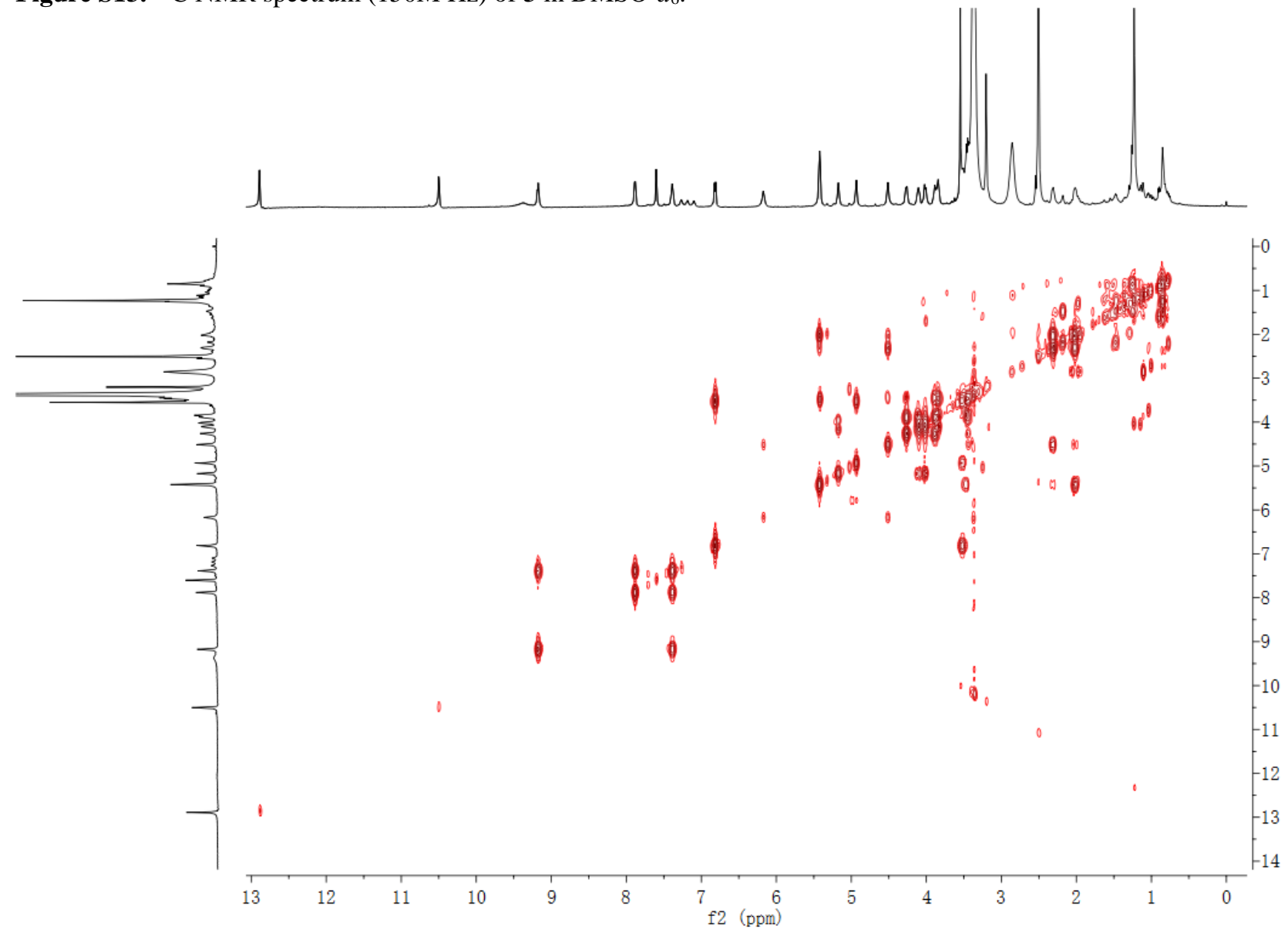

Figure S14. COSY spectrum (600 MHz) of 3 in DMSO- $d_{6}$. 


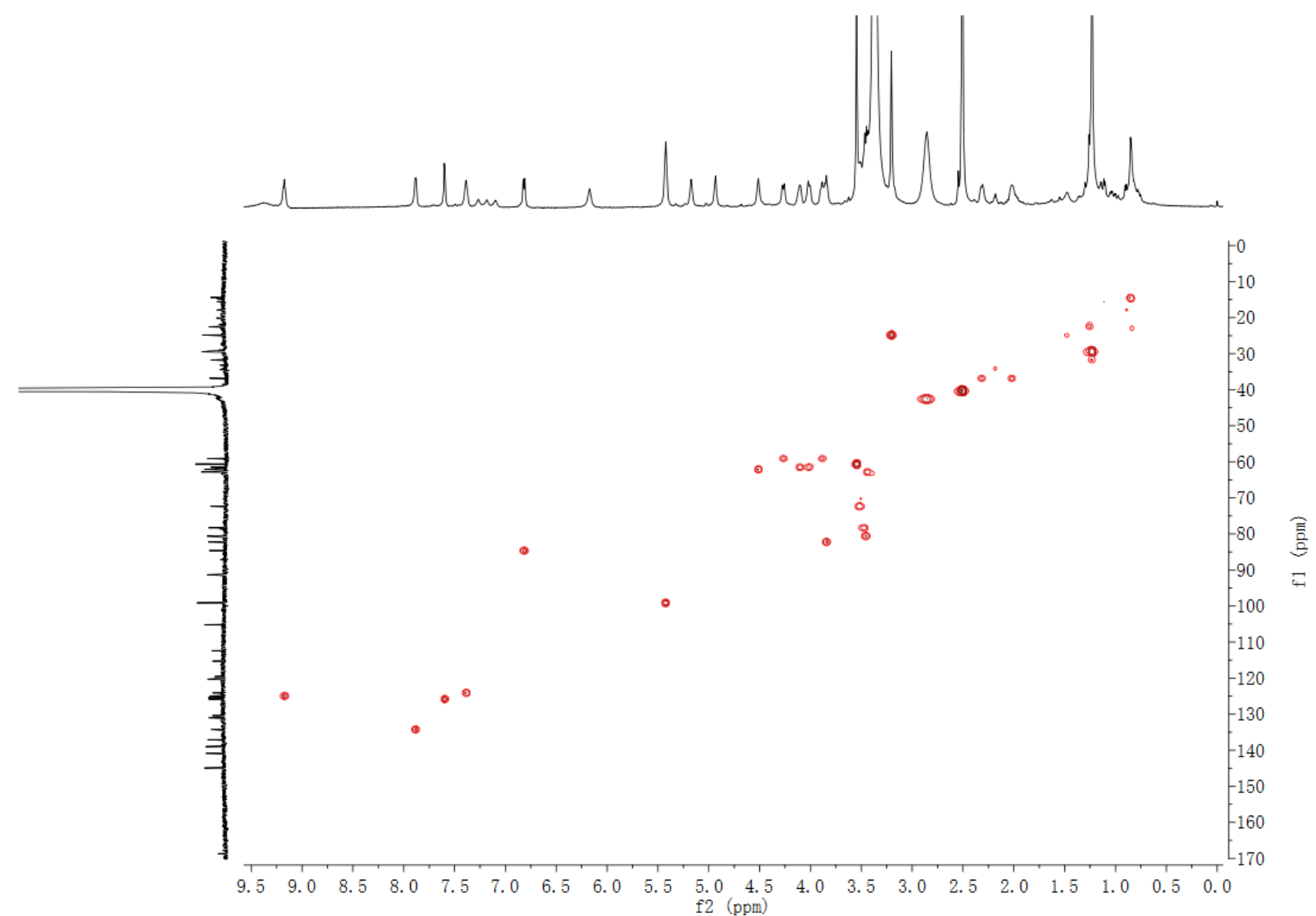

Figure S15. HSQC spectrum (600 MHz) of 3 in DMSO- $d_{6}$. 

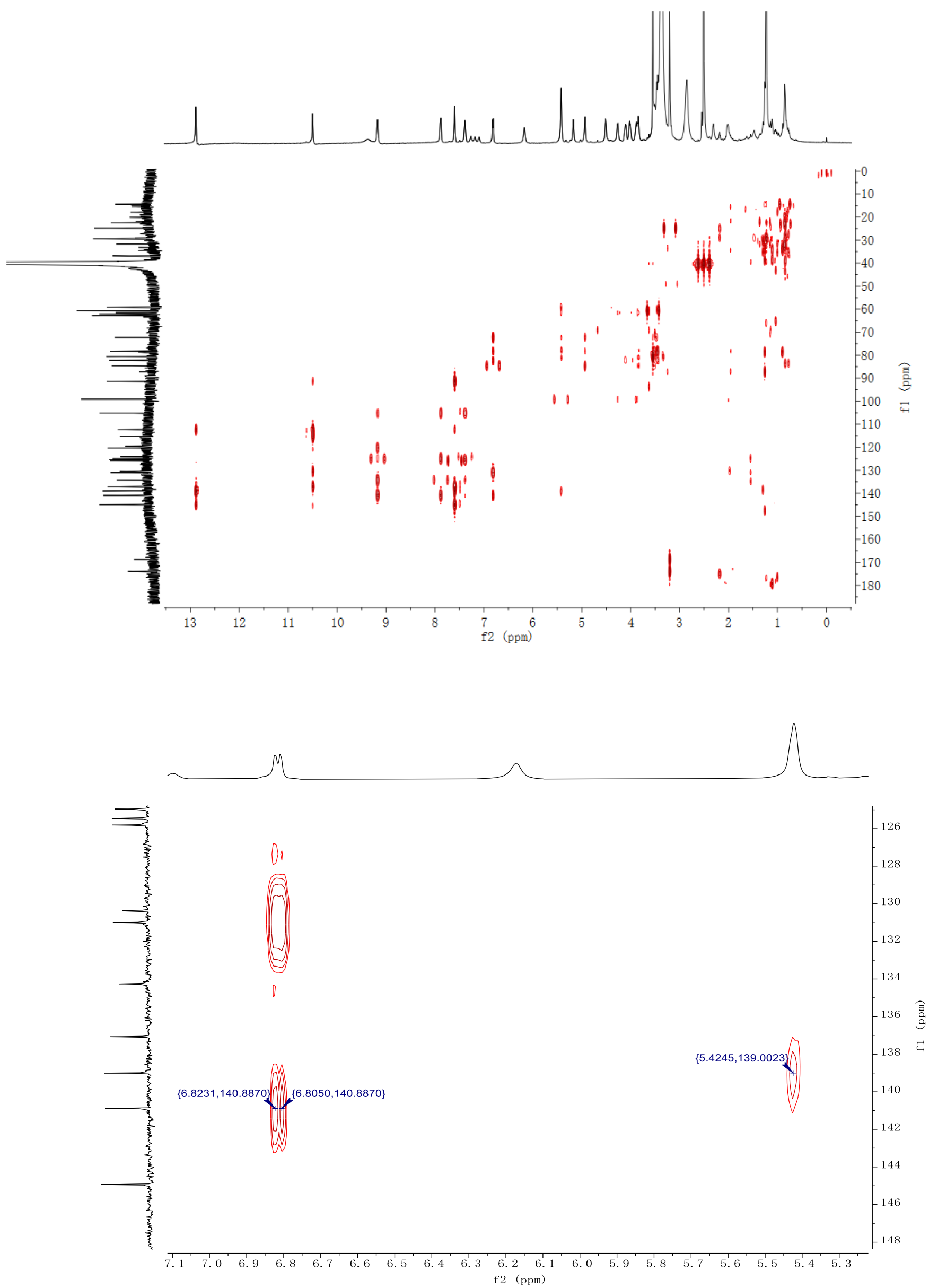

Figure S16. HMBC spectrum $(600 \mathrm{MHz})$ of 3 in DMSO- $d_{6}$. 

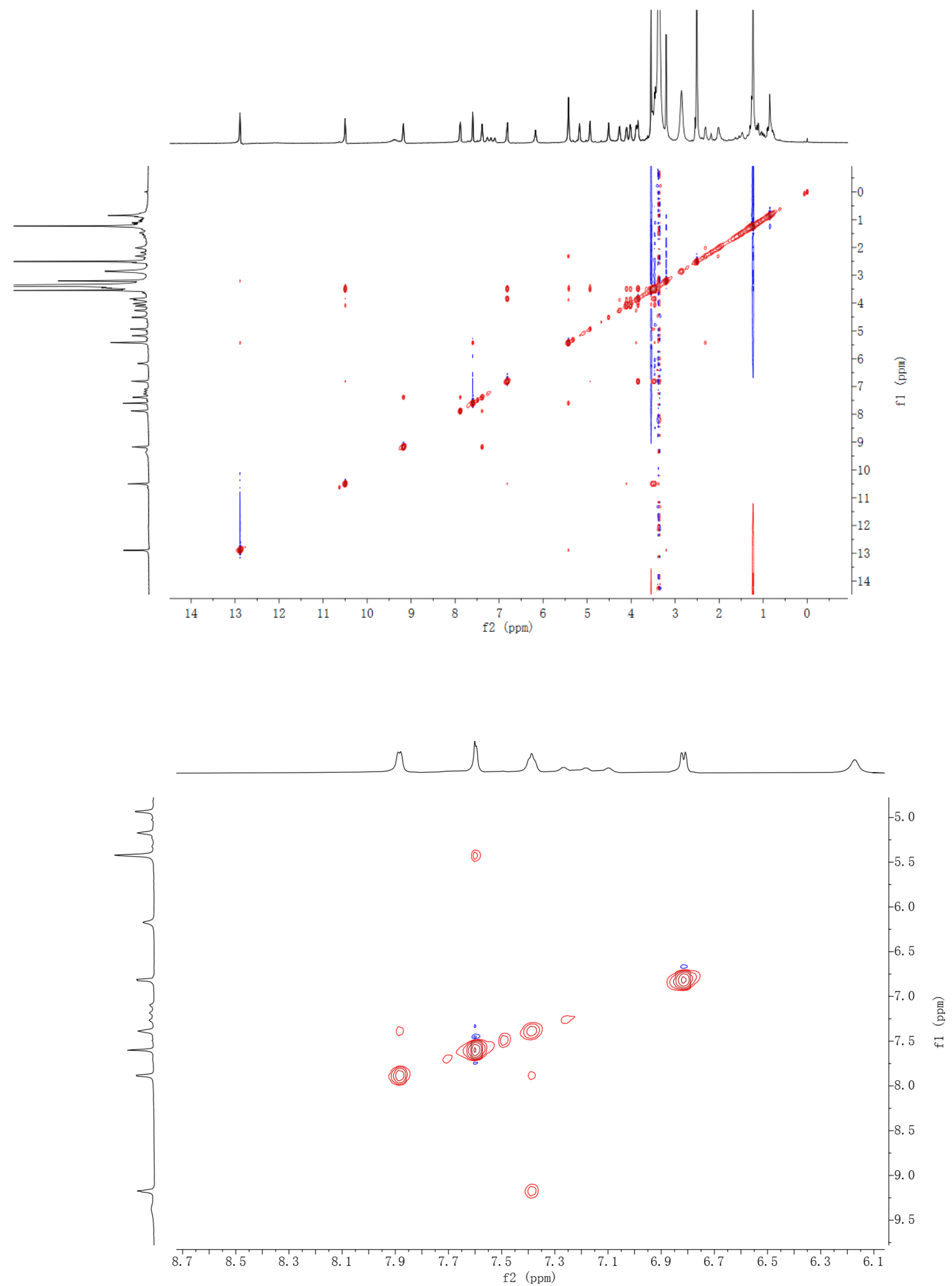

Figure S17. NOESY spectrum (600 MHz) of 3 in DMSO- $d_{6}$ 


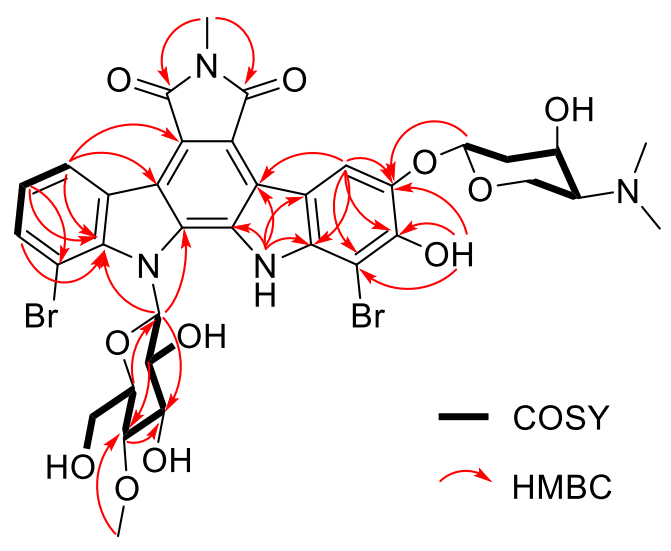

Figure S18. Key 2D correlation of loongmycinC (3).
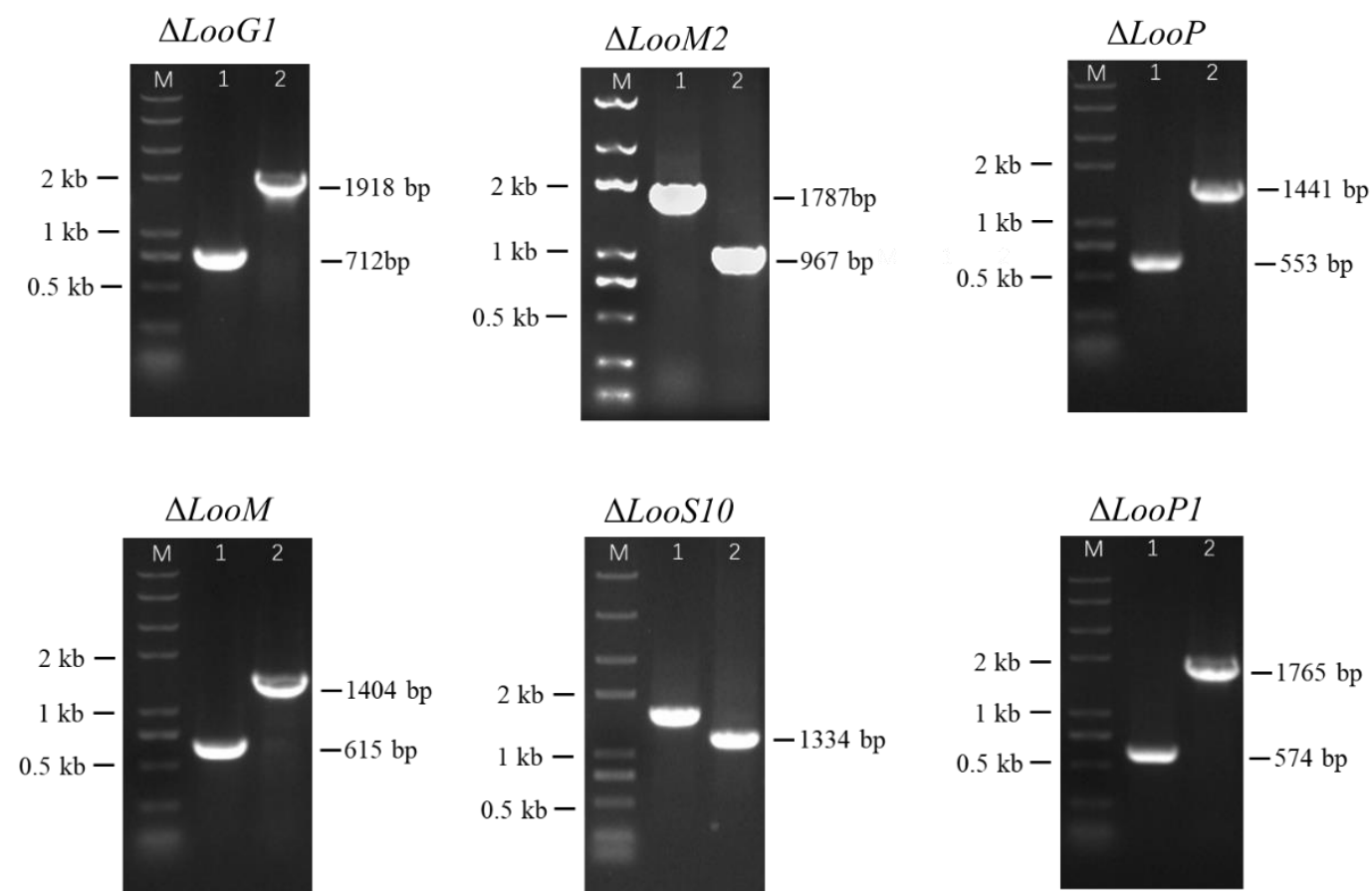

Figure S19. PCR verification for gene mutants. A) Lane1, amplified from $\Delta l o o G 1$ mutant; Lane 2, amplified from wt cosmid 31P9. B) Lane1, amplified from $\Delta$ looM2 mutant; Lane 2, amplified from wt cosmid 31P9. C) Lane1, amplified from $\Delta$ looP mutant; Lane 2, amplified from wt cosmid 31P9. D) Lane1, amplified from $\Delta$ looM mutant; Lane 2, amplified from wt cosmid 31P9. E) Lane1, amplified from $\Delta l o o S 10$ mutant; Lane 2, amplified from wt cosmid 31P9. F) Lane1, amplified from $\triangle$ looP1 mutant; Lane 2, amplified from wt cosmid 31P9. 
i) S. lividans K4-114/31P9

ii) S. lividans K4-114/31P9- $/$ /ooP1

iii) S. lividans K4-114/31P9- $\Delta / 00 P$

iv) S. lividans K4-114/31P9- $/$ /ooM

v) S. lividans K4-114/31P9-AlooM2

vi) S. lividans K4-114/31P9--L/ooS10

vii) S. lividans K4-114/31P9--/ooG1

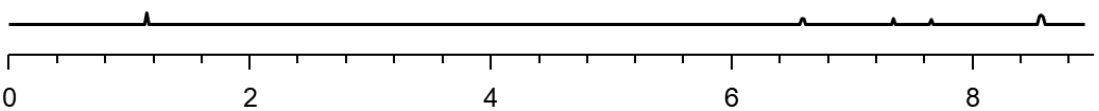

Figure S20. LC-MS analysis for heterologous production of loonamycin C (3). i) S. lividans K4-114 strain carrying 31P9 plasmid; ii) S. lividans K4-114 strain carrying $31 \mathrm{P} 9$ plasmid where looP1 gene was deleted; iii) S. lividans K4-114 strain carrying 31P9 plasmid where looP gene was deleted; iv) S. lividans K4-114 strain carrying 31P9 plasmid where looM gene was deleted; v) S. lividans K4-114 strain carrying 31P9 plasmid where looM2 gene was deleted; vi) S. lividans K4-114 strain carrying 31P9 plasmid where looS10 gene was deleted; iii) S. lividans K4-114 strain carrying $31 \mathrm{P} 9$ plasmid where looG1 gene was deleted.

\section{Reference}

(1) Zhang, B.; Xu, Z.; Teng, Q.; Pan, G.; Ma, M.; Shen, B. Angew. Chem. Int. Ed. 2017, 56, 7247-7251. 